\title{
JURISPRUDÊNCIA E EMENTÁRIO
}

\author{
JURISPRUDENCE AND ABRIDGEMENT OF LAW
}

DIREITO ADMINISTRATIVO SANITÁRIO - CONSELHOS PROFISSIONAIS - Conselho Regional de Farmácia. Aplicação de multa por falta de responsável. Competência. Lei n. 3.820/60, Art. 24. Conforme o disposto no art. 24 da Lei n. 3.820/60, "As empresas e estabelecimentos que exploram serviços para os quais são necessárias atividades de profissional farmacêutico deverão provar perante os Conselhos Federal e Regionais, que essas atividades são exercidas por profissional habilitado e registrado", sendo que "aos infratores deste artigo será aplicada pelo respectivo Conselho Regional à multa.... . A Lei n. 5.911/73, em seu art. 44, restringiu a competência dos órgãos responsáveis da vigilância sanitária apenas para "verificação das condições de licenciamento e funcionamento" das farmácias e drogarias, o que, à evidência, não afasta a competência dos Conselhos Regionais para fiscalizar a existência de responsável técnico nos referidos estabelecimentos e, ainda, aplicar multa pelo descumprimento dessa obrigação, a teor do art. 24 da Lei n. 3.820/60. Percebe-se, portanto, que os Conselhos Regionais de Farmácia têm competência para fiscalizar e apenar as drogarias que não comprovarem a existência de responsável técnico habilitado e devidamente registrado. Precedentes deste Tribunal e do e. Superior Tribunal de Justiça. Apelação provida. Remessa oficial prejudicada. A Turma, por unanimidade, deu provimento à apelação, prejudicada a remessa oficial.

Tribunal Regional Federal $1^{2}$ Região

Apelação em Mandado de Segurança 2000.01.00.027506-3

Relator: Desembargador João Batista Moreira

Decisão: 16 de setembro de 2002.

DIREITO ADMINISTRATIVO SANITÁRIO - MEIOS DE CONTROLE PRODUTOS - Mandado de Segurança. Registro de medicamentos. Agência Nacional de Vigilância Sanitária - ANVISA. Vigilância Sanitária. Perda 
de objeto. Extinção do processo sem julgamento de mérito. A ANVISA exerce 0 poder de polícia sanitária sobre os medicamentos de um modo geral, portanto todo registro deve observar as normas por ela editadas, especialmente, quando se trata de produto destinado ao consumo humano, não configurando exigência nesse sentido abuso de poder. A concessão do registro requerida suplantou a discussão, fazendo extinguir o interesse da empresa apelante na revisão da sentença que lhe restou desfavorável. Perde a apelação $\circ$ objeto, se o objetivo do impetrante é alcançado, havendo, assim, perda do interesse de agir, autorizando a extinção do processo, sem julgamento de mérito.

Tribunal Regional Federal Região

Apelação em Mandado de Segurança 2001.34.00.017191-0 /DF

Relator: Desembargador Tourinho Neto

Decisão: 13 de agosto de 2002.

\section{DIREITO ADMINISTRATIVO SANITÁRIO - MEIOS DE CONTROLE -} PRODUTOS - Ação Rescisória. Ato normativo a propósito de padrão de identidade e qualidade de águas acondicionadas de sais. Edição por autoridade da Secretaria de Vigilância Sanitária. Competência. Por força da disposição inscrita no inciso VI do artigo 200 da Lei Fundamental, compete ao sistema único de saúde fiscalizar e inspecionar alimentos, compreendido o controle de seu teor nutricional, bem como bebidas e águas para consumo humano, cabendo à direção nacional desse sistema, em virtude do disposto no artigo 16, inciso VIII, da Lei n. 8.080, de 1990, a função de "estabelecer critérios, parâmetros e métodos para o controle da qualidade sanitária de produtos, substâncias e serviços de consumo e uso humano". Legitimidade da edição, pela Secretaria de Vigilância Sanitária do Ministério da Saúde, da Portaria n. 328, de $1^{2}$ de dezembro de 1985 , que dispôs a respeito de padrão de identidade e qualidade de águas acondicionadas de sais, contendo definição, composição, fatores de qualidade, critérios de higiene, métodos de análise e de amostragem, rotulagem e forma de registro das mesmas. Inexistência de ofensa ao quanto disposto nas normas legais indicadas como fundamento do pleito rescisório. Ação rescisória que se julga improcedente. A Seção, por unanimidade, julgou improcedente a ação rescisória.

Tribunal Regional Federal $1^{\mathrm{a}}$ Região

Ação Rescisória 1998.01.00.029110-8 /DF

Relator: Juiz Carlos Moreira Alves

Decisão: 20 de março de 2002. 
DIREITO CONSTITUCIONAL SANITÁRIO - Ação Cautelar. Liberação do plantio e comercialização de soja geneticamente modificada (soja round up ready), sem o prévio estudo de impacto ambiental - Art. 225 , $\S 1^{2}$, IV, da $\mathrm{CF} / 88 \mathrm{c} / \mathrm{c}$ arts. $8^{2}, 9^{\circ}$ e $10^{\circ}, \S 4^{2}$, da Lei $n .6 .938 / 81$ e art. $1^{2}, 2^{\circ}$, capute $\S 1^{2}$, $3^{2}, 4^{2}$ e anexo $\mathrm{I}$, da resolução Conama $\mathrm{n}$. 237/97. Inexistência de norma regulamentadora quanto à liberação de descarte, no meio ambiente, de OGM - Princípio da precaução e da instrumentalidade do processo cautelar. Presença do Fumus Boni luris e do Periculum in Mora. Poder geral de cautela do magistrado. Inexistência de julgamento extra petita - Art. 808, III, do CPC. Improcedência da alegação de julgamento extra petita, mesmo porque, na ação cautelar, no exercício do poder geral de cautela, pode o magistrado adotar providência não requerida e que the pareça idônea para a conservação do estado de fato e de direito envolvido na lide. A sentença de procedência da ação principal não prejudica ou faz cessar a eficácia da ação cautelar, que conserva a sua eficácia na pendência do processo principal - e não apenas até a sentença - mesmo porque os feitos cautelar e principal têm natureza e objetivos distintos. Inteligência do art. 808, II, do CPC. Se os autores só reconhecem ao IBAMA a prerrogativa de licenciar atividades potencialmente carecedoras de degradação ambiental, não há suporte à conclusão de que a mera expedição de parecer pela CNTBio, autorizando o plantio e a comercialização de soja transgênica, sem o prévio estudo de impacto ambiental, possa tornar sem objeto a ação cautelar, na qual os autores se insurgem, exatamente, contra o aludido parecer. $\mathrm{O}$ art. 225 da CF/88 erigiu o meio ambiente ecologicamente equilibrado "a bem de uso comum do povo e essencial à sadia qualidade de vida, impondo-se ao Poder Público e à coletividade o dever de defendê-lo e preservá-lo para as presentes e futuras gerações", incumbindo ao poder Público, para assegurar a efetividade desse direito, "exigir, na forma da lei, para instalação de obra ou atividade potencialmente causadora de significativa degradação do meio ambiente, estudo prévio de impacto ambiental, a que se dará publicidade" (art. $225, \S 1^{\ell}$, IV, da CF/88). A existência do fumus boni iuris ou da probabilidade de tutela, no processo principal, do direito invocado, encontra-se demonstrada especialmente: a) pelas disposições dos arts. $8^{9}, 9^{9}$ e $10^{9}, \S 4^{2}$, da Lei $n .6 .938$, de 31.8 .81 - recepcionada pela CF/88 - e dos arts. $1^{2}, 2^{2}$, caput e $\S 1^{\circ}, 3^{2}, 4^{2}$ e Anexo I da Resolução CONAMA n. 237/97, à luz das quais se infere que a definição de "obra ou atividade potencialmente causadora de significativa degradação do meio ambiente", a que se refere o art. $225, \S 1^{2}, \mathrm{IV}$, da CF/88, compreende "a introdução de espécies exóticas e/ou geneticamente modificadas", tal como consta do Anexo I da aludida Resolução CONAMA n. 237/ 97, para a qual, por via de conseqüência, necessário o estudo prévio de impacto ambiental, para o plantio, em escala comercial, e a comercialização de sementes de soja geneticamente modificadas, especialmente ante séria dúvida quanto à Constitucionalidade do art. $2^{\circ}$, XVI, do Decreto n. 1.752/95, 
que permite a CNTBIO dispensar o prévio estudo de impacto ambiental de competência do IBAMA - em se tratando de liberação de organismos geneticamente modificados, no meio ambiente, em face do veto presidencial à disposição constante do projeto da Lei n. 8.974/95, que veiculava idêntica faculdade outorgada à CNTBIO. Precedente do STF (ADIN n. 1.086-7/SC, Rel. Min. Ilmar Galvão, in DJU de 16/09/94, p. 24279); c) pela vedação contida no art. $8^{2}$, VI, da Lei n. 8.974/95, diante da qual se conclui que a CNTBIO deve expedir, previamente, a regulamentação relativa à liberação e descarte, no meio ambiente, de organismos geneticamente modificados, sob pena de se tornarem ineficazes outras disposições daquele diploma legal, pelo que, à máquina de norma regulamentadora a respeito do assunto, até o momento presente, juridicamente relevante é a tese de impossibilidade de autorização de qualquer atividade relativa à introdução de OGM no meio ambiente; d) Pelas disposições dos arts. $8^{2}$, VI, e 13, V, da Lei n. 8.974/95, que sinalizam a potencialidade lesiva de atividade cujo descarte ou liberação de OGM, no meio ambiente, sem a observância das devidas cautelas regulamentares, pode causar, desde incapacidade para as ocupações habituais por mais de 30 dias e lesão corporal grave, até a morte, lesão ao meio ambiente e lesão grave ao meio ambiente, tal como previsto no art. $13, \S \S 1^{\mathrm{l}}$ a 3 , da Lei n. 8.974/95, tipificando-se tais condutas como crimes e impondo-Ihes severas penas. A existência de uma situação de perigo recomenda a tutela cautelar, no intuíto de se evitar - em homenagem aos princípios da precaução e da instrumentalidade do processo cautelar -, até o deslinde da ação principal, o risco de dano irreversível e irreparável ao meio ambiente e à saúde pública, pela utilização de engenharia genética no meio ambiente e em produtos alimentícios, sem a adoção de rigorosos critérios de segurança. Homologação do pedido de desistência do IBAMA para figurar no pólo ativo da lide, em face da superveniência da Medida Provisória n. 1.984-18, de 19.6.2000. Preliminares rejeitadas, Apelações e remessa oficial, tida como interposta, improvidas. A Turma, por unanimidade, homologou o pedido de desistência formulado pelo Instituto Brasileiro do Meio Ambiente e dos Recursos Naturais Renováveis - IBAMA; por maioria, rejeitou a preliminar de prejudicialidade da ação cautelar e, por unanimidade, rejeitou as demais preliminares. No mérito, negou provimento às Apelaçōes e à Remessa Oficial, tida como interposta.

Tribunal Regional Federal Região

Apelação Cível 2000.01.00.014661-1/DF

Relator: Juíza Assusete Magalhães

Decisão: 08 de agosto de 2000.

DIREITO ADMINISTRATIVO SANITÁRIO - RESPONSABILIDADE. Falecimento de neonato em hospital público. Nexo causal entre a morte e o trata- 
mento administrado. Responsabilidade objetiva do Estado. Teoria do risco administrativo. Falecimento de neonato por infecção generalizada contraída através de soro glicosado contaminado, utilizado para alimentar prematuros do Hospital Alexander Fleming. Laudo de necropsia comprovando que a patologia foi adquirida, uma vez que a criança nasceu saudável. Configuração de nexo causal entre o tratamento ministrado no hospital público federal e a morte prematura do neonato por infecção adquirida. Responsabilidade objetiva do Estado, com base na Teoria do Risco Administrativo, amparado na Carta Magna, em seu artigo $37, \S 6^{2}$. Configurada a responsabilidade da União, tanto sob o aspecto da atuação omissiva, como da atuação comissiva. A despeito de inexistir reparação para o sofrimento ocasionado pela perda de um filho, o valor arbitrado para a indenização dos danos morais deve englobar um montante suficiente para compensar a dor sofrida, como para punir o agente, não podendo ser inexpressivo e tampouco exacerbado. $V$ ) Recurso e remessa parcialmente providos para reduzir a verba honorária a $10 \%$ (dez por cento) e determinar a aplicação da correção monetária sobre o valor fixado, na forma da lei.

Tribunal Regional Federal $2^{\mathrm{a}}$ Região

Apelação Cível 96.02.21044-3

Relator: Juíza Maria Helena Cisne

Decisão: 09 de setembro de 1998.

DIREITO PENAL SANITÁRIO - Apelação criminal - art. 16 da Lei n. 6.368/ 76. Substância química. Cloreto de etila. Resolução n. 04 da Agência Nacional de Vigilância Sanitária. Abolitio Criminis. Extinção de punibilidade. Provimento do apelo. Decisão unânime. A Agência Nacional de Vigilância Sanitária, equivocadamente, através da Resolução n. 04, de 6.12.2000, publicada no Diário Oficial da União de 7.12.2000, incluindo o Cloreto de Etila na Lista "D2", referente aos insumos químicos que não são proibidos, não obstante republicação no dia 15.12.2000, incluindo na Lista "B1", como substâncias psicotrópicas de uso proscrito, beneficiou os imputados pelo crime estipulado pela Lei n. 6.368/76, extinguindo a punibilidade, ante o instituto da Abolitio Criminis.

Tribunal de Justiça de Minas Gerais

Apelação Criminal: 2001134020

Relator: Juiz José Alves Neto

Decisão: 23 de maio de 2002.

DIREITO CIVIL SANITÁRIO - RESPONSABILIDADE - Indenização. Erro médico. Relação de causalidade entre $O$ dano sofrido pela vítima e $O$ ato 
culposo do médico. Prova Pericial. Embora em assuntos que exijam conhecimentos técnicos específicos, os julgadores, via de regra, se embasem nas provas periciais produzidas, eles não estão necessariamente adstritos ao laudo, mormente quando existam nos autos elementos comprobatórios robustos que colidem com as conclusões apresentadas pelo perito. Inteligência da norma do art. 436, do CPC. Estabelecendo-se o nexo de causalidade entre 0 dano sofrido pela vítima e 0 ato culposo do médico, impōe-se que aquela seja indenizada, pelos danos materiais e morais que the foram causados. Valoração dos danos morais. Cabe ao prudente arbitrio do Magistrado, fixar o quantum referente à indenização por danos morais, devendo sopesar, dentre outros fatores, a gravidade do fato, a magnitude do dano, a extensão das seqüelas sofridas pela vítima, a intensidade da culpa, as condições econômicas e sociais das partes envolvidas, de forma a proporcionar ao ofendido uma satisfação pessoal, de maneira a amenizar o sentimento do seu infortúnio. Embargos acolhidos

Tribunal de Justiça de Minas Gerais

Embargos: 2001134020

Relator: Juiz Pinheiro Lago

Decisão: 13 de agosto de 2002.

\section{DIREITO ADMINISTRATIVO SANITÁRIO - MEIOS DE CONTROLE -} SERVIÇOS - Mandado de Segurança. Vigilância Sanitária. Farmácia. Ampliação do objeto do estabelecimento. "Drugstore". Negativa de expedição de alvará. Concessão da segurança. Sentença confirmada. Em face da nova legislaçāo, pode a "drugstore" funcionar no mesmo estabelecimento das drogarias e farmácias, respeitadas algumas exigências, sofrendo estas a fiscalização da vigilância sanitária, cabendo ao Conselho de Farmácia fiscalizar a atuação dos farmacêuticos. Age com excesso de poderes o encarregado da vigilância sanitária, ao deixar de proceder à vistoria para expedição de Alvará do SUS em estabelecimento que ampliou seu objeto social, fundando seu ato em Resolução. Em reexame necessário, confirmaram a sentença, prejudicado o recurso voluntário.

Tribunal de Justiça de Minas Gerais

Processo: 000217121-3/00

Relator: Juiz José Francisco Bueno

Decisão: 19 de outubro de 2001.

DIREITO SANITÁRIO AMBIENTAL - Ação Civil Pública - Meio ambiente. Água contaminada. Liminar. Saúde da população. Nos termos do art. 225, 
da Constituição Federal, todos têm direito ao meio ambiente ecologicamente equilibrado, bem de uso comum do povo e essencial à sadia qualidade de vida, impondo-se ao Poder Público e à coletividade o dever de defendê-lo e preservá-lo para as presentes e futuras gerações. É cabível medida liminar para interditar a freqüência às águas de cachoeiras contaminadas, conforme constatação feita em laudos técnicos acostados pelo Ministério Público, poi ter sido detectada a presença, em grau elevado, de moluscos transmissores de esquistossomose. Negaram provimento.

Tribunal de Justiça de Minas Gerais

Processo: 000264792-3/00

Relator: Juiz Wander Marotta

Decisão: 8 de abril 2002

DIREITO ADMINISTRTIVO SANITÁRIO - MEIOS DE CONTROLE - SERVIÇOS - Mandado de Segurança. Liminar. Indeferimento. Interdição de estabelecimento comercial (panificadora). Falta de licença sanitária e de alvará de localização. Ademais, infringência a princípios elementares de higiene e saúde. Ausência da fumaça do bom direito. Requisitos do art. $7^{9}$ da Lei n. 1.533/51. Não configurados. Agravo de instrumento. Recurso improvido. $\mathrm{Na}$ interdição de estabelecimento comercial pela autoridade sanitária, impõe-se sempre preservar o interesse da coletividade, resguardando a saúde pública. Vistos, relatados e discutidos estes autos de Agravo de Instrumento n. 111.329-9 de Curitiba $-2^{2}$ Vara da Fazenda Pública em que é agravante Vitor Romboli ME e agravado Secretário de Saúde do Município de Curitiba. Trata-se de agravo de instrumento contra decisão interlocutória que indeferiu liminar em mandado de segurança. Aduz a agravante que o agravado não fundamentou o Termo de Intimação n. 303/5 de 7.5.01; que lavrou outro termo, omitindo qual a razão e a que assunto administrativo tratava o termo inicial não cumprido pela agravante; após, o agravado lavrou outros termos contra a agravante, inclusive por não possuir licença sanitária; nunca foi notificada para apresentar a licença sanitária, bem como para realizar as exigências da Saúde Pública; não ocorreu regular notificação do proprietário e responsável; violação do devido processo legal; presentes os requisitos do fumus boni iuris e do periculum in mora. Recurso preparado e respondido. A douta Procuradoria Geral da Justiça opinou pelo improvimento do recurso. A controvérsia reside na autuação da agravante pela Saúde Pública e interdição do seu estabelecimento comercial (panificadora). Ingressou com mandado de segurança, que se negou liminar. $O$ presente recurso ataca a aludida decisão. Em primeiro lugar, a agravante não comprovou sequer que possui licença sanitária e alvará de localização para o exercício de sua atividade comercial, como exige o art. 39 da Lei Municipal n. 9.000, de 27 de dezembro de 1996. Em segundo lugar, deixou de se com- 
provar de plano que Clemar de Fátima Vitorassi não possuía autorização para receber notificação da autoridade sanitária, máxime porque realizada no estabelecimento comercial da agravante, tudo indicando que se tratava de preposto da agravante. Em terceiro lugar, as provas documentais anexadas aos autos comprovam de maneira clara e inequivoca que o estabelecimento comercial da agravante infringiu os princípios elementares de higiene e saúde. É um verdadeiro atentado à saúde da comunidade. Deve prevalecer 0 interesse público sobre $o$ individual. Ausente o requisito da aparência do bom direito em favor da agravante. Assim sendo, o recurso não merece provimento. Posto isso, acordam os julgadores integrantes da $4^{\mathrm{a}}$ Câmara Cível do Tribunal de Justiça do Estado do Paraná, por unanimidade de votos, negar provimento ao recurso.

Tribunal de Justiça do Paraná

Relator: Juiz Lauro Laertes de Oliveira

Processo: 111329900

Número do Acórdão: 19274

Decisão: 3 de outubro de 2001. 